\title{
CLINICAL, RADIOLOGICAL AND PATHOLOGICAL CORRELATION OF THYROID NODULE
}

\author{
Shekapppa C. Malagimani1, Nagareddy S. Patil², Kasasomasekhar ${ }^{3}$ \\ ${ }^{1}$ Associate Professor, Department of General Surgery, VIMS, Bellary. \\ 2Postgraduate Student, Department of General Surgery, VIMS, Bellary. \\ 3Professor, Department of General Surgery, VIMS, Bellary.
}

ABSTRACT
BACKGROUND
Nodular thyroid is a common clinical entity. The optimum diagnostic strategy for the patient with nodular thyroid is still a matter
of debate. The goal of diagnostic workup now is to select those patients for surgery, who have a high likelihood of harbouring
malignancy in the thyroid nodules.
The present study was undertaken to evaluate the efficacy of FNAC and USG in differentiating benign and malignant nodules.

\section{MATERIALS AND METHODS}

A prospective study was carried out on 100 patients from 11 - 70 years' age group of both sexes, presenting with thyroid nodules to Dept. of Surgery, VIMS, Bellary during the period of November 2014 - November 2016. All patients were evaluated clinically and subjected to FNAC and USG of thyroid. The results of clinical diagnosis, FNAC and USG was compared with histopathology reports.

\section{RESULTS}

Majority of the cases presented were females between the age group of 21 - 30 years. Swelling in the anterior neck was the presenting complaint in all 100 cases. The sensitivity and specificity of FNAC and USG in diagnosing malignant lesions was 35.7\%, $57.1 \%$ and $98.8 \%, 95.3 \%$ respectively.

\section{CONCLUSION}

The commonest presentation was from the females in the age group of 21 - 30 years with swelling in the anterior neck. Overall rate of malignancy rate was $14 \%$. No single investigation was found to be $100 \%$ sensitive or specific in diagnosing malignancy in nodular goitre but a good clinical, FNAC and USG examinations are complimentary to each other in predicting malignancy and avoid unnecessary or inadequate surgery.

\section{KEYWORDS}

Fine Needle Aspiration Cytology (FNAC), Ultrasonography (USG).

HOW TO CITE THIS ARTICLE: Malagimani SC, Patil NS, Kasasomasekhar. Clinical, radiological and pathological correlation of thyroid nodule. J. Evolution Med. Dent. Sci. 2017;6(26):2137-2141, DOI: 10.14260/Jemds/2017/464

\section{BACKGROUND}

Thyroid gland is unique among endocrine organs, as it is the largest endocrine gland in the body and the first to develop in foetal life. There is approximately 4\% - 5\% incidence of clinically apparent thyroid nodules in the general population.[1] Thyroid nodules are about four times more common in females than in males. The majority (90\%) of thyroid nodules are benign as malignancy occurs in only 1 in 10 thyroid nodules.[2] The overall incidence of malignancy in solitary thyroid nodule ranges between $10 \%$ and $30 \% \cdot[1],[3]$

The goal of diagnostic workup now is to select those patients for surgery who have a high likelihood of harbouring malignancy in the nodule. ${ }^{[4]}$ Among these diagnostic workup, Ultrasonography (USG) and Fine Needle Aspiration Cytology (FNAC) are commonly used, but there are drawbacks of each technique and the final answer to the problem is still elusive. ${ }^{[5]}$

Financial or Other, Competing Interest: None.

Submission 21-02-2017, Peer Review 18-03-2017,

Acceptance 23-03-2017, Published 30-03-2017.

Corresponding Author:

Dr. Shekapppa C. Malagimani,

$B / 24$, Staff Quarters,

VIMS (OPD) Cantonment,

Bellary.

E-mail:doc_shekar@yahoo.com

DOI: $10.14260 /$ jemds $/ 2017 / 464$

(c) $(i) \$$
The present study was undertaken to evaluate the utility of FNAC in preoperative diagnosis of nodular goitre and to evaluate the efficacy of USG and FNAC differentiating between benign and malignant nodules.

\section{Objectives}

1. To correlate clinical diagnosis with investigative parameters, i.e. Ultrasonography and fine needle aspiration cytology and histopathology in the evaluation of thyroid nodule.

2. To evaluate the sensitivity and specificity of USG and FNAC and their reliability in submitting the thyroid swellings to the surgery.

\section{MATERIALS AND METHODS}

This is a hospital based case series study, was conducted in the Department of Surgery during the period of two years from November 2014 - November 2016. All patients were evaluated clinically and were subjected to FNAC and USG of thyroid. Patients who were admitted for surgery, thyroid specimen obtained is subjected for Histopathology. The results of clinical diagnosis, FNAC and USG were compared with post-operative Histopathology reports.

\section{Source of Data}

The patients visiting Department of General Surgery for Goitre and getting admitted in our hospital between Nov. 2014 - Nov. 2016 were taken up for the study. 


\section{Sample Size}

All the patients presenting with Goitre who were subjected for surgery between Nov. 2014 - Nov. 2016.

\section{Study Design}

Observational study- hospital based case series.

\section{Inclusion Criteria}

All the patients who were presented with Solitary or Multinodular Goitre to the Department of General Surgery during the period of two years from November 2014 November 2016

\section{Exclusion Criteria}

1. Patients who were not subjected to surgery.

2. Patients who were not fit for surgery due to comorbid conditions, eg. CCF, Chronic liver disease, etc.

3. Patients with diffuse goitre or autoimmune goitres.

\section{Method of Collection of Data}

Source of data is from the patients who were presented with Goitre in the surgical OPD and admitted for the same in the hospital from Nov. 2014 - Nov. 2016.

All the patients who were presented with Goitre satisfying inclusion and exclusion criteria were enrolled in the study and were put through a predesigned proforma of clinical details (clinical data, examination findings) and investigations (routine, USG, FNAC). Further these reports were correlated with the post-operative HPE reports.

\section{Duration of Study}

The study was conducted for a period of two years from November 2014 to November 2016 at VIMS, Bellary.

All patients were examined clinically after taking a detailed history. Then, they were investigated with FNAC and USG of the thyroid using high resolution 7.3 $\mathrm{MHz}$ probe.

The results of FNAC were interpreted as benign, malignant, suspicious and inadequate aspirate. Sonographically, the nodules were evaluated for size, location, echo texture, margins, presence of halo, calcification, vascularity, accessory nodules, associated cervical lymphadenopathy and consistency (solid, cystic or mixed) in order to differentiate between benign and malignant nodules.

Then, all the patients were subjected to surgery and Histopathological Examination (HPE) of the specimen obtained. Finally, the histopathology reports were correlated with the findings of FNAC and USG in order to evaluate their sensitivity and specificity by statistical methods.

\section{RESULTS}

\begin{tabular}{|c|c|c|}
\hline Complaints & Frequency & Percentage \\
\hline Swelling in front of neck & 100 & 100 \\
\hline Swelling associated with pain & 05 & 05 \\
\hline Difficulty in breathing & 01 & 01 \\
\hline Difficulty in swallowing & 06 & 06 \\
\hline Change of voice & 00 & 00 \\
\hline $\begin{array}{c}\text { Hypo/hyperthyroidism } \\
\text { features }\end{array}$ & 00 & 00 \\
\hline \multicolumn{2}{|c|}{ Table 1. Distribution based on Complaints } \\
\hline
\end{tabular}

Swelling was present in all the cases (100\%). Swelling associated with pain was present in $5 \%$ of cases, difficulty of swallowing was present in $6 \%$ of cases and difficulty breathing was seen in a single case. Features of hyperthyroidism or hypothyroidism were not seen in any of the patients.

\begin{tabular}{|c|c|c|c|}
\hline Sl. & \multirow{2}{*}{ No. } & \multirow{2}{*}{ Classification } & \multicolumn{2}{|c|}{ FNAC Lesions } \\
\cline { 3 - 4 } & & Category & No. \\
\hline \multirow{3}{*}{1} & \multirow{3}{*}{ Benign (n = 82) } & Nodular goitre & 22 \\
\cline { 3 - 4 } & & Colloid nodule & 34 \\
\cline { 3 - 4 } & & $\begin{array}{c}\text { Nodular goitre with } \\
\text { Adenomatous hyperplasia }\end{array}$ & 19 \\
\cline { 3 - 4 } & & Hashimoto's thyroiditis & 01 \\
\hline 2 & Suspicious (n = 12) & Follicular neoplasia & 12 \\
\hline 3 & Malignant (n = 06) & Papillary carcinoma & 06 \\
\hline 4 & Inadequate (nil) & \multicolumn{2}{|c|}{ Nil } \\
\hline \multicolumn{2}{|c|}{ Total (100) } & $\mathbf{1 0 0}$ \\
\hline \multicolumn{3}{|c|}{ Table 2. Distribution based on FNAC Findings } \\
\hline
\end{tabular}

On FNAC, benign group occupies major group (82\%) followed by suspicious $(12 \%)$ and malignant $(6 \%)$. There is no inadequate or insufficient cytological smear. Nodular goitre is the most common benign lesion consisting of 41 cases, out of which 19 cases were showing adenomatous hyperplasia changes; 34 cases were colloid nodule; 6 cases were positive for malignancy showing PCT.

\begin{tabular}{|c|c|c|}
\hline Nodular goitre with Adenomatous hyperplasia & 8 & 8.0 \\
\hline Benign cystic lesion & 2 & 2.0 \\
\hline Benign follicular adenoma & 15 & 15.0 \\
\hline Colloid nodule & 35 & 35.0 \\
\hline Hurthle cell adenoma & 2 & 2.0 \\
\hline Marginal B cell lymphoma & 1 & 1.0 \\
\hline Nodular goitre & 24 & 24.0 \\
\hline Papillary carcinoma of thyroid & 13 & 13.0 \\
\hline Total & $\mathbf{1 0 0}$ & $\mathbf{1 0 0 . 0}$ \\
\hline
\end{tabular}

Table 3. Distribution based on HPE Diagnosis

HPE diagnosis revealed that the most common lesion was colloid nodule (35\%) followed by nodular goitre (32\%), benign follicular adenoma (15\%); 8 out of $32 \mathrm{NG}$ cases were showing adenomatous hyperplasia; $13 \%$ of cases were papillary carcinoma and 1 case was reported as marginal B cell lymphoma.

\begin{tabular}{|c|c|c|}
\hline Category & Lesion & No. of Cases \\
\hline \multirow{2}{*}{$\begin{array}{c}\text { Benign } \\
(\mathrm{n}=88)\end{array}$} & Cystic & 15 \\
\cline { 2 - 3 } & Hyperechoic nodule & 35 \\
\cline { 2 - 3 } & MNG & 38 \\
\hline \multirow{2}{*}{$\begin{array}{c}\text { Suspicious } \\
(\mathrm{n}=10)\end{array}$} & Suspicious MNG & 07 \\
\cline { 2 - 3 } & $\begin{array}{c}\text { Suspicious mixed } \\
\text { echogenic }\end{array}$ & 03 \\
\hline Malignant (n = 02) & Mixed & 02 \\
\hline \multicolumn{2}{|c|}{ Total } & $\mathbf{1 0 0}$ \\
\hline \multicolumn{2}{|c|}{ Table 4. Distribution based on USG } \\
\hline
\end{tabular}


The most common finding in USG was benign lesions (88\%) followed by suspicious (10\%) and malignancy (02\%). Among benign, most common lesion was multinodular goitre followed by hyperechoic nodule. MNG.

Among suspicious, most common lesion was suspicious

\begin{tabular}{|c|c|c|}
\hline FNAC & Frequency & Percentage \\
\hline Malignant & 6 & 6.0 \\
\hline Benign & 94 & 94.0 \\
\hline Total & $\mathbf{1 0 0}$ & $\mathbf{1 0 0 . 0}$ \\
\hline \multicolumn{2}{|c|}{ Table 5. Distribution based on FNAC } \\
\hline
\end{tabular}

In FNAC, malignancy was present in $6 \%$ of cases.

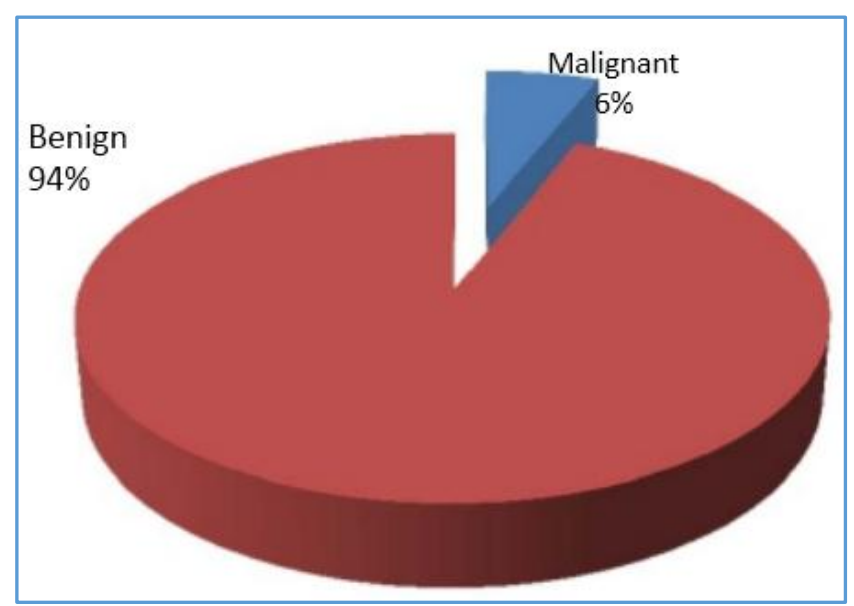

Pie Chart showing Malignant and Benign Lesion on FNAC

\begin{tabular}{|c|c|c|}
\hline HPE & Frequency & Percentage \\
\hline Malignant & 14 & 14.0 \\
\hline Benign & 86 & 86.0 \\
\hline Total & $\mathbf{1 0 0}$ & $\mathbf{1 0 0 . 0}$ \\
\hline \multicolumn{2}{|c|}{ Table 6. Distribution based on HPE } \\
\hline
\end{tabular}

In HPE, malignancy was present in $14 \%$ of cases.

\begin{tabular}{|c|c|c|c|}
\hline \multirow[b]{2}{*}{ HPE Diagnosis } & \multicolumn{2}{|c|}{ Clinical Diagnosis } & \multirow[b]{2}{*}{ Total } \\
\hline & $\begin{array}{c}\text { Multinodular } \\
\text { Goitre }\end{array}$ & $\begin{array}{c}\text { Solitary } \\
\text { Nodule }\end{array}$ & \\
\hline $\begin{array}{c}\text { Nodular goitre with } \\
\text { adenomatous hyperplasia }\end{array}$ & 3 & 5 & 8 \\
\hline Benign cystic lesion & 0 & 2 & 2 \\
\hline Benign follicular adenoma & 2 & 13 & 15 \\
\hline Colloid nodule & 15 & 20 & 35 \\
\hline Hurthle cell adenoma & 1 & 1 & 2 \\
\hline Marginal B cell lymphoma & 1 & 0 & 1 \\
\hline Nodular goitre & 14 & 10 & 24 \\
\hline $\begin{array}{c}\text { Papillary carcinoma of } \\
\text { Thyroid }\end{array}$ & 9 & 4 & 13 \\
\hline Total & 45 & 55 & 100 \\
\hline \multicolumn{4}{|c|}{ Table 7. HPE Diagnosis v/s Clinical Diagnosis } \\
\hline
\end{tabular}

Among 100 cases, clinically 45 cases were multinodular and 55 cases were solitary nodule. Among clinically diagnosed multinodular goitres, colloid nodule was most common benign lesion (33.3\%); 22\% (10 cases) were malignant. Out of 10 malignant lesions, 9 were PCT and 1 was marginal B cell lymphoma. Among clinically diagnosed solitary nodules, colloid nodule was most common benign lesion (36.3\%); $7.2 \%$ ( 4 cases) were malignant and all were reported as PCT.

\begin{tabular}{|c|c|c|c|c|c|c|c|c|}
\hline \multirow{3}{*}{ HPE } & \multicolumn{7}{|c|}{ USG } & \multirow{3}{*}{ Total } \\
\hline & \multicolumn{4}{|c|}{ Benign (88) } & \multirow{2}{*}{\begin{tabular}{c|}
$\begin{array}{c}\text { Malign- } \\
\text { ancy (02) }\end{array}$ \\
MEN \\
$(02)$
\end{tabular}} & \multicolumn{2}{|c|}{$\begin{array}{c}\text { Suspicious } \\
\text { (10) }\end{array}$} & \\
\hline & $\begin{array}{c}C \\
(14) \\
\end{array}$ & $\begin{array}{c}\text { DN } \\
(01) \\
\end{array}$ & $\begin{array}{c}\text { HN } \\
(35) \\
\end{array}$ & $\begin{array}{l}\text { MNG } \\
(38) \\
\end{array}$ & & $\begin{array}{c}\text { SMEN } \\
(03)\end{array}$ & \begin{tabular}{|c|} 
SMNG \\
$(07)$ \\
\end{tabular} & \\
\hline $\mathrm{NG}+\mathrm{AH}$ & 1 & 0 & 4 & 3 & 0 & 0 & 0 & 8 \\
\hline BCL & 1 & 0 & 1 & 0 & 0 & 0 & 0 & 2 \\
\hline BFA & 0 & 0 & 11 & 1 & 0 & 2 & 1 & 15 \\
\hline $\mathrm{CN}$ & 7 & 0 & 13 & 15 & 0 & 0 & 0 & 35 \\
\hline $\mathrm{HA}$ & 0 & 0 & 1 & 0 & 0 & 0 & 1 & 2 \\
\hline MBL & 0 & 0 & 0 & 0 & 0 & 0 & 1 & 1 \\
\hline $\mathrm{NG}$ & 5 & 1 & 3 & 15 & 0 & 0 & 0 & 24 \\
\hline PCT & 0 & 0 & 2 & 4 & 2 & 1 & 4 & 13 \\
\hline Total & 14 & 01 & 35 & 38 & 02 & 03 & 07 & 100 \\
\hline & & & & & $/ s t$ & & & \\
\hline
\end{tabular}

USG revealed 2 malignant cases and among them HPE diagnosed 2 as papillary carcinoma thyroid, i.e. prediction of malignancy is $100 \%$. USG revealed 10 suspicious cases and among them HPE diagnosed 6 as malignancy, in that 5 were papillary carcinoma thyroid and 1 was MBL. Prediction of malignancy in suspicious lesions is $60 \%$.

Among suspicious lesions, SMNG (71.4\%) has got more chances of harbouring malignancy than SMEN (33.3\%). Benign lesions in USG harbouring malignancy in decreasing order MNG $(10.5 \%)>$ HN $(5.7 \%)$.

\section{DISCUSSION}

In the present study, age of the patient ranged from $11-70$ yrs. with median age of $35 \mathrm{yrs}$. Maximum proportion of study subjects were in the age group of 21 - 33 years (33\%) followed by 41 - 50 years (23\%), 31 - 40 years (21\%), 51 - 60 years $(12 \%)$ and $11-20$ years $(10 \%)$. These findings correlate with studies conducted by Chowdary et al[6] Hanumanthappa,[7] who suggested occurrence of multinodular goitre in 2nd and 3rd decade of life.

Swelling was present in all the cases (100\%). Pain in the swelling was present in 5\% of cases, difficulty of swallowing was present in $6 \%$ of cases and difficulty of breathing was present in $1 \%$ of cases. This is similar to other studies of Zhu et al,[8] Andrew Holden[9] and Varverakis et al..[10]

The main presenting complaint of the patients apart from thyroid swelling was dysphagia, which was present in $6 \%$ of the cases. Thyroid nodules are very common clinical entities. Clinical palpation suggests a prevalence of thyroid nodules in $1 \%-7 \%$ of the general population.[11] Nodular swellings consist of benign and malignant tumours as well as disorders that consist of non-neoplastic hyperplasia. The overwhelming majority of thyroid nodules are benign with the incidence of malignancy being only 5\%.[12] Polyzos et al conducted a similar study in 941 patients who presented with palpable thyroid nodules. They hypothesised that male gender, solitary nodule and nodule diameter $>$ or $=4.5 \mathrm{~cm}$ predispose to higher risk for thyroid malignancy in patients presenting with thyroid nodules.[13] 
FNAC contributes significantly to the preoperative investigation in patients with thyroid swelling, but despite its well-recognised value there are limitations to the technique. The reported pitfalls are those related to specimen adequacy,[14] sampling techniques, poor localisation, unguided FNAC, the skill of the aspirator performing the aspirations, the experience of the cytopathologist interpreting the aspirate and overlapping cytological features between benign and malignant follicular neoplasms and inadequate, indeterminate FNAC. One major limitation of thyroid cytology is its inability to distinguish between follicular adenoma from follicular carcinoma.[15] This diagnosis require detail histological examination for vascular or capsular invasion and cannot be reliably made on routine FNAC specimens.[16]

Hence, follicular neoplasm (lesion) is given as diagnosis in FNAC. Cystic lesions of thyroid should undergo surgical excision or close followup, as these can harbour PTC which can be missed as FNAC smears may not be representative. Owing to their small size papillary microcarcinomas also can get missed in FNAC. In this study, benign group occupies major group (82\%) followed by malignant (6\%) and suspicious $(12 \%)$. There is no inadequate or insufficient cytological smear.

FNAC showed $6 \%$ malignant cases. Among malignant lesions, papillary carcinoma was the most common. Carcinoma of the thyroid is the most common malignancy of endocrine system comprising $0.6 \%$ and 1.6 of all cases of malignant neoplasm in men and women respectively.

Taking into consideration Histopathology as a Gold standard, correlation of FNAC finding with histopathology finding was done.

In this study among benign thyroid swelling (82\%) nodular goitre was common $41 \%$, followed by colloid nodule which was $34 \%$. The study reported by Md. Shafiqul Islam showed 78\% non-neoplastic and 22\% neoplastic. (Papillary carcinoma $15.56 \%$ and follicular lesion 3.3\%).[17]

While comparing FNAC with Histopathological Examination (HPE) in the present study, it was found that out of 34 cases of colloid goitre, 29 cases were diagnosed as colloid goitre in HPE; out of $41 \mathrm{NG}$ proved to be 28 in HPE; out of $28 \mathrm{NG}$ in HPE 7 cases were showing adenomatous hyperplasia changes.

FNAC revealed 6 malignant cases all as PCT and among them HPE diagnosed 5 as Papillary Carcinoma Thyroid (PCT).

In this study out of FNAC diagnosed 12 cases of follicular neoplasm, 91.6\% were benign in HPE. A study reported 15\% - 30\% of FNA diagnosed follicular neoplasm were actually carcinomas; remaining 70\% - 85\% were benign. ${ }^{[12]}$ Another study observed that the diagnosis "follicular neoplasm" is indeterminate; $70 \%$ are benign. ${ }^{[9]}$

In our study, it was found that benign lesions in FNAC which have got high chances of harbouring malignancy in decreasing order are BCL (33.3\%) > NG + AH (15.7\%) $>$ NG $(9.0 \%)$. No colloid nodule cytology was found to be harbouring malignancy in HPE.

In the present study we found sensitivity and specificity of FNAC to be $35.7 \%$, the $98.8 \%$ respectively. Several international studies have documented the sensitivity of FNAC in thyroid nodules to range from 38\% - 98\%.[8,9,12,13]
Similarly, the international normal range is for specificity is $72 \%$ to $100 \%[102,107]$ and for PPV is $50 \%$ to $90 \%$. The negative predictive value derived from this audit was $73.1 \%$. In a report of 19 studies and 20 series by Lewis et al 2009,[18] the reported and re-calculated mean for negative predictive value was $84 \%$ and $93 \%$. So present study is fairly comparable to other studies.

\begin{tabular}{|c|c|}
\hline Statistical Measurement & Percentage (\%) \\
\hline Accuracy for satisfactory specimens & $>95$ \\
\hline False-negative rate & $0.7-11$ \\
\hline False-positive rate & $0-7$ \\
\hline Negative predictive value & $89-98$ \\
\hline Negative predictive value & $94-99$ \\
\hline Sensitivity & $43-98$ \\
\hline Specificity & $72-100$ \\
\hline
\end{tabular}

The thyroid nodules on USG were subdivided into 3 groups- benign, suspicious and malignant on the basis of various sonographic features. Features suggestive of malignancy on USG are- hypoechoic pattern, incomplete peripheral halo, irregular margins, internal microcalcification, increased vascularity, presence of cervical lymphadenopathy and peripheral degeneration in mixed nodules. Features suggestive of benign diseases on USG arehalo sign (transonic uniform rim surrounding the mass), variable echogenicity, multinodularity, large cystic lesion, diffusely nodular inhomogeneous gland and peripheral calcification. In our study, USG revealed 2 malignant cases and among them HPE diagnosed 2 as papillary carcinoma thyroid, i.e. prediction of malignancy is $100 \%$. USG revealed 10 suspicious cases and among them HPE diagnosed 5 as papillary carcinoma thyroid 1 as MBC lymphoma and 3 as benign follicular adenoma. Prediction of malignancy in suspicious lesions is $60 \%$.

Among suspicious lesions, SMNG (71.4\%) has got more chances of harbouring malignancy than SMEN (33.3\%). Benign lesions in USG harbouring malignancy in decreasing order MNG $(10.5 \%)>$ HN $(5.7 \%)$. We found the sensitivity and specificity of USG as $57.1 \%$ and $95.3 \%$ respectively for differentiation between the benign and malignant nodules. Watters et al (1992) found that the sensitivity and specificity of USG in suggesting a malignant lesion were $74 \%$ and $83 \%$ respectively. They interpreted an USG report as suggestive of malignancy if the nodule was solid or of a mixed solid-cystic variety and an hypoechoic and non-haloed lesion. They emphasised that the USG has added advantage of allowing the whole gland to be examined rather than the dominant nodule, but was limited by the fact that no features were pathognomonic for malignancy, so that it should be regarded as a complementary rather than an alternative investigation to FNAC in the management of solitary thyroid nodules. Jones et al found that the sensitivity and specificity were $75 \%$ and $61 \%$. It has been observed that for a thyroid nodule to be detected by palpation it must be at least $1 \mathrm{~cm}$ in diameter, while USG can detect nodules as small as $3 \mathrm{~mm}$ in diameter.

Surgery occupies an important place in the management of thyroid nodules. A hemithyroidectomy is often the definitive procedure in most non-neoplastic and some neoplastic nodules. A nodular or colloid goitres may require subtotal thyroidectomy. 
Suspicious or malignant cytopathology may require a total thyroidectomy with or without radical neck dissection. The commonest performed surgery was total thyroidectomy, which accounts for 49 (49\%) cases. Functional neck dissection was done in 8 cases of papillary carcinoma of thyroid, where lymph nodes were palpable. Hemithyroidectomy was done for 2 malignant solitary nodules which was inadequate, later completion total thyroidectomy was done.

\section{CONCLUSION}

The present study was undertaken to evaluate the usefulness of clinical examination with correlation of FNAC and USG of nodular thyroid considering HPE as Gold standard in the management of thyroid goitre and compare the efficacy of each of the investigation-

- Incidence of malignancy is more common in MNG $(22.2 \%)$ than SN (7.2\%).

- BCL cytology is though deceptive warrants repeat or USG-guided FNAC.

- Adenomatous hyperplasia in FNAC of nodular goitre has got increased chances of harbouring malignancy.

- Colloid nodule cytology has got least chances of harbouring malignancy.

- $\quad$ As FNAC is considered a screening procedure, particular attention should be given to minimising false-negative diagnoses.

- However, USG fairly helps in characterisation of thyroid nodules, but cannot be taken as a single tool in assessing malignancy. It aids in deciding which nodule should undergo FNAC. Direction of fine needle aspiration biopsy can be best accomplished with sonography.

Ultimately, no single investigation was found to be $100 \%$ sensitive or specific in diagnosing malignancy in nodular goitre but a good clinical, FNAC and USG examinations are complimentary to each other in predicting malignancy and avoid unnecessary or inadequate surgery.

\section{REFERENCES}

[1] Altavilla G, Pascale M, Nenci I. Fine needle aspiration cytology of thyroid gland disease. Acta cytologica 1990;34(2):251-6.

[2] Matesa N. FNAC of the thyroid. Acta Clin Croat 2002;41:23-131.

[3] Bouvet M, Feldman JI, Gill GN, et al. Surgical management of the thyroid nodule: patient selection based on the results of fine-needle aspiration cytology. Laryngoscope 1992;102(12 Pt 1):1353-6.

[4] Kapur. Solitary thyroid nodule. Indian Journal of Surgery 1999;44:174-9.
[5] Watters DA, Ahuja AT, Evans RM, et al. Role of ultrasound in the management of thyroid nodules. Am J Surg 1992;164(6):654-7.

[6] Chowdhury J, Das S, Maji D. A study of thyroid nodules: diagnostic correlation between fine needle aspiration cytology and histopathology. J Indian Med Assoc 2008;106(6):389-90.

[7] Hanumanthappa MB, Gopinathan S, Suvarna R, et al. The incidence of malignancy in multi-nodular goitre: a prospective study at a tertiary academic centre. Journal of Clinical and Diagnostic Research 2012;6(2):267-70.

[8] Zhu-Q. Pre-operative examination of patients with thyroid nodules by high resolution real time ultrasound. Chung Hua Chung Lu Isa Chih 1993;15(5):385-7.

[9] Holden A. The role of colour and duplex doppler ultrasound in the assessment of thyroid nodules. Australasian Radiology Journal 1995;39(4):343-9.

[10] Varverakis E, Neonakis E. Contribution of highresolution ultrasonography in the differential diagnosis of benign from malignant thyroid nodules. Hormones (Athens) 2002;1(1):51-6.

[11] Kim N, Lavertu P. Evaluation of a thyroid nodule. Otolaryngol Clin N Am 2003;36:17-33.

[12] Castro MR, Gharib H. Thyroid fine-needle aspiration biopsy: progress, practice and pitfalls. Endocrine practice 2003;9(2):128-36.

[13] Polyzos SA, Kita M, Efstathiadou Z, et al. The use of demographic, ultrasonographic and scintigraphic data in the diagnostic approach of thyroid nodules. Exp Clin Endocrinol Diabetes 2009;117(4):159-64.

[14] Lowhagen T, Willems JS, Lundell G, et al. Aspiration biopsy cytology in diagnosis of thyroid cancer. World J Surg 1981;5(1):61-73.

[15] Anderson JB, Webb AJ. Fine-needle aspiration biopsy and the diagnosis of thyroid cancer. Br J Surg 1987;74(4):292-6.

[16] Miller JM, Kini SR, Hamburger JI. The diagnosis of malignant follicular neoplasms of the thyroid by needle biopsy. Cancer 1985;55(12):2812-7.

[17] Shafiqul I, Belayat HS, Nasima A, et al. Comparative study of FNAC and histopathology in the diagnosis of thyroid swelling. Bangladesh J of Otorhinolaryngology 2010;16(1):35-43.

[18] Lewis CM, Chang KP, Pitman M, et al. Thyroid fineneedle aspiration biopsy: variability in reporting. Thyroid 2009;19(7):717-23. 